Check for updates

National Institute for Health Research, London, UK

elaine.maxwell@nihr.ac.uk Cite this as: $B M / 2021 ; 373: n 1173$ http://dx.doi.org/10.1136/bmi.n1173 Published: 19 May 2021

\section{Unpacking post-covid symptoms}

\author{
Common, burdensome, and highly variable
}

\section{Elaine Maxwell scientific adviser}

Our understanding of long covid (also known as post-covid syndrome) has progressed considerably since the first follow-up of people discharged from hospital in 2020 after SARS-CoV-2 infection. ${ }^{12}$ People who were not admitted to hospital with their covid-19 infection but who have enduring symptoms have driven the wider recognition of long covid symptoms, including organ impairment. ${ }^{3}$ Much evidence comes from small, observational studies or surveys using different case definitions and sampling frames, resulting in a wide range of prevalence estimates. ${ }^{4}$ Larger surveys found that enduring symptoms were more often reported among people who had had covid-19 than among controls who had not, 56 including reporting of cognitive deficits. ${ }^{7}$ However, reliance on self-reporting in many studies has been criticised by some commentators.

In a linked paper, Daugherty and colleagues (doi:10.1136/bmj.n1098) used a large electronic records dataset to describe the prevalence and risks of post-covid sequelae in patients both admitted to hospital and in the community in the United States. ${ }^{8}$ Several studies have retrospectively reviewed ICD-10 (international classification of diseases, 1oth revision) codes in electronic health records, including a large study reporting that people admitted to hospital with covid-19 were 3.5 times more likely to be readmitted and 7.7 times more likely to die within five months of discharge than controls admitted to hospital without covid-19. ${ }^{9}$ Researchers using US Department of Veterans Affairs databases found increased use of analgesics, antidepressants, antihypertensives, and oral hypoglycaemics in the six months after confirmed covid-19 compared with controls, ${ }^{10}$ and data from the US TriNetX electronic health records network showed that nearly $34 \%$ of people testing positive for SARS-CoV-2 had a neurological or psychiatric diagnosis in the following six months. ${ }^{11}$

Daugherty and colleagues found that certain conditions were more commonly diagnosed after covid-19 than after other viral lower respiratory tract infections. ${ }^{8}$ The estimated $14 \%$ incidence of new diagnoses up to six months after SARS-CoV-2 infection is strikingly similar to the $13.7 \%$ incidence of self-reported symptoms lasting more than 12 weeks found by the UK Office for National Statistics. ${ }^{6}$ While both studies report higher incidence in people admitted to hospital, new symptoms and diagnoses were also seen in those who remained at home. ${ }^{6} 810$ The absolute number of people reporting long covid symptoms will be higher in the community owing to the (at least) 10-fold difference in the numbers admitted to hospital and those who stayed at home. ${ }^{12}$ Primary care clinicians should expect patients with mild initial infections to report long covid or post-covid symptoms just as frequently as those who were critically ill.

In common with most studies, Daugherty and colleagues report that enduring symptoms are more common in women, those living with social deprivation, and those with pre-existing comorbidities. ${ }^{8}$ Importantly, they found that $10 \%$ of people developed new diagnoses requiring medical attention more than three weeks after the initial infection, with $4 \%$ developing more than one new diagnosis. This feature is well described by people with real life experience, who call it the “corona-coaster.” People who present with late onset symptoms (particularly those not admitted to hospital) report that some healthcare professionals do not associate symptoms with covid-19 and do not provide appropriate assessment and treatment. ${ }^{4}$

It is too early to predict how long clinical sequelae will persist after covid-19, but these symptoms clearly create a major personal burden for many people, with some individuals experiencing difficulty returning to work and some unable to care for dependents. ${ }^{4}$ Long covid is also putting a strain on healthcare services, which have been already decimated by the pandemic. Identifying risk factors would facilitate triage and faster access to specialist care. However, one of the peculiarities of long covid is its non-linear progression, hampering attempts to predict who will develop particular symptoms and when. Risk factors differ for different new diagnoses, suggesting that a variety of mechanisms could be at play. ${ }^{81011}$ Applying these risk factors to clinical practice will probably need long covid to be subdivided into more specific phenotypes.

Daugherty and colleagues' analyses included people aged 18-65, and although symptom reporting is less common outside this age band, ${ }^{6}$ evidence is growing that children also experience long covid..$^{1314}$ In older adults, symptoms could be under-reported because of assumptions that they are due to aging or comorbidities. Healthcare professionals should be alert to the possibility of long covid in anyone with confirmed or suspected covid-19. How to treat these longer term consequences is now an urgent research priority.

The BMJ has judged that there are no disqualifying financial ties to commercial companies. The authors declare the following other interests: The views expressed are those of the author and not necessarily those of the NIHR. Further details of The BMJ's policy on financial interests is here: https://www.bmj.com/sites/default/files/attachments/resources/2016/03/16-current-bmj-education-coi-form.pdf.

Provenance and peer review: Commissioned; not peer reviewed.

I am grateful for the helpful comments on a draft made by Jo House, member of the NIHR Centre for Engagement and Dissemination's Long Covid Patient Reference Group. 
1 Carfi A, Bernabei R, Landi FGemelli Against COVID-19 Post-Acute Care Study Group. Persistent symptoms in patients after acute COVID-19. JAMA 2020;324:603-5.

doi: 10.1001/jama.2020.12603 pmid: 32644129

2 Mandal S, Barnett J, Brill SE, etal. 'Long-COVID': a cross-sectional study of persisting symptoms, biomarker and imaging abnormalities following hospitalisation for COVID-19. Thorax 2021;76:396-8doi: 10.1136/thoraxjnl-2020-215818.

3 Dennis A, Wamil M, Alberts J, etalCOVERSCAN study investigators. Multiorgan impairment in low-risk individuals with post-COVID-19 syndrome: a prospective, community-based study. BMJ Open 2021;11:e048391.pmid: 33785495

4 National Institute for Health Research. Living with Covid19 - second review. 2021. https://evidence.nihr.ac.uk/themedreview/living-with-covid19-second-review/. doi: 10.3310/themedreview_45225

5 Cirulli E, Barrett KM, Riffle S, etal. Long-term COVID-19 symptoms in a large unselected population.medRxiv [Preprint] 2020. https://www.medrxiv.org/content/10.1101/2020.10.07.20208702v1

6 Office for National Statistics. Prevalence of ongoing symptoms following coronavirus (COVID-19) infection in the UK: 2021. https://www.ons.gov.uk/peoplepopulationandcommunity/healthandsocialcare/conditionsanddiseases/bulletins/prevalenceofongoingsymptomsfollowingcoronaviruscovid19infectionintheuk/1april2021

7 Hampshire A, Trender W, Chamberlain S, etal. Cognitive deficits in people who have recovered from COVID-19 relative to controls: An N=84285 online study.medRxiv [Preprint] 2020. doi: 10.1101/2020.10.20.20215863.

8 Daugherty SE, Guo Y, Heath K, etal. Risk of clinical sequelae after the acute phase of SARS-CoV-2 infection: retrospective cohort study. BMJ2021;373:n1098.

9 Ayoubkhani D, Khunti K, Nafilyan V, etal. Post-covid syndrome in individuals admitted to hospital with covid-19: retrospective cohort study. BMJ 2021;372:n693. doi: 10.1136/bmj.n693 pmid: 33789877

10 Al-Aly Z, Xie Y, Bowe B. High-dimensional characterization of post-acute sequalae of COVID-19. Nature 2021. doi: 10.1038/s41586-021-03553-9. pmid: 33887749

11 Taquet M, Geddes JR, Husain M, Luciano S, Harrison PJ. 6-month neurological and psychiatric outcomes in 236379 survivors of COVID-19: a retrospective cohort study using electronic health records. Lancet Psychiatry2021;8:416-27. doi: 10.1016/S2215-0366(21)00084-5 pmid: 33836148

12 Department of Health and Social Care Coronavirus. Coronavirus (COVID-19) in the UK. 2021. https://coronavirus.data.gov.uk/

13 Buonsenso D, Munblit D, De Rose C, etal. Preliminary evidence on long COVID in children. Acta Paediatr 2021. doi: 10.1111/apa.15870. pmid: 33835507

14 Osmanov IM, Spiridonova E, Bobkova P, etal. Risk factors for long covid in previously hospitalised children using the ISARIC Global follow-up protocol: A prospective cohort study.medRxiv [Preprint] 2021. https://www.medrxiv.org/content/10.1101/2021.04.26.21256110v1

This article is made freely available for use in accordance with BMJ's website terms and conditions for the duration of the covid-19 pandemic or until otherwise determined by BMJ. You may use, download and print the article for any lawful, non-commercial purpose (including text and data mining) provided that all copyright notices and trade marks are retained. 